This study examines differences in the independent and interdependent self-construals of American and East Asian students studying in the United States and the influence of these self-construals on coping and stress. Path analysis revealed that the importance of the independent self-construal was positively related to direct coping strategies, which predicted reduced levels of stress for the international students. Ratings of the importance of the interdependent self-construal were positively related to increased stress for the Asian students. The self-construals and direct coping were the strongest predictors of stress for East Asian students; variables commonly identified in other research addressing cross-cultural adaptation (e.g., number of host country friends, relationships with conationals, language ability, and previous cross-cultural experience) did not significantly predict stress for the international students. The effects of the self-construals and coping were moderated by culture, however, and were not predictive of perceived stress for American students.

\title{
SELF-CONSTRUALS, COPING, AND STRESS IN CROSS-CULTURAL ADAPTATION
}

\author{
SUSAN E. CROSS \\ University of Michigan
}

Many researchers have probed the processes and obstacles involved in cross-cultural adjustment. However, several investigators have voiced concern over the atheoretical nature of much of this work (Church, 1982; Furnham, 1988; Kealey, 1989). In response to this concern, this study examines the cross-cultural adjustment of students from the perspective of recent theoretical and empirical developments in the psychology of the self

\begin{abstract}
AUTHOR'S NOTE: This research was based in part on a doctoral dissertation under the direction of Hazel R. Markus at the University of Michigan. Thanks are due to committee members James S. Jackson, Nancy Cantor, and Luis Gomez for their helpful advice. James Jackson and the University of Michigan Rackham School of Graduate Studies provided resources and information vital to this study. I am also grateful to Margie Cohen for her help sending and receiving questionnaires. Frank Wicker, Alan Reifman, Amanda Harrist, and Jeanne Schillaci provided helpful feedback on the manuscript. Thanks are also due to Richard Brislin and Yoshi Kashima for their thoughtful reviews and suggestions. This research was supported by Grant 1F31 MH09970-01 from the National Institute for Mental Health, and completion of this article was facilitated by a Spencer Post-Doctoral Fellowship award. Portions of this article were presented at the annual convention of the American Psychological Association, San Francisco, August 1991. Correspondence concerning this article should be addressed to Susan E. Cross, who is now at the Department of Psychology, W112 Lagomarcino Hall, Iowa State University, Ames, IA 50011 (e-mail: s2.sxc@isumvs.iastate.edu).
\end{abstract}

JOURNAL OF CROSS-CULTURAL PSYCHOLOGY, Vol. 26 No. 6, November 1995 673-697

(C) 1995 Western Washington University 
(Markus \& Kitayama, 1991; Markus \& Wurf, 1987; Triandis, 1989; Triandis, Bontempo, Villareal, Asai, \& Lucca, 1988). Once given shape and form by culture, an individual's self-system organizes experience, directs behavior, and provides meaning and coherence to the person's life (Baumeister, 1987; Greenwald \& Praktanis, 1984; Markus \& Wurf, 1987). Consequently, the self plays an important role in psychological well-being as an individual adjusts to a new culture.

\section{CULTURE AND THE SELF}

\section{INDIVIDUALISM AND THE INDEPENDENT SELF-CONSTRUAL}

Cultural beliefs, values, and institutions mold the structure and content of the self. One aspect of culture that influences the self is the relative importance of individualism or collectivism (Hofstede, 1980, 1991; Markus \& Kitayama, 1991; Triandis, 1989; Triandis, Bontempo, Villareal, Asai, \& Lucca, 1988). Markus and Kitayama (1991) suggest that the normative tasks of persons in an individualist culture are to be unique, to "stand out" (Weisz, Rothbaum, \& Blackburn, 1984), to express their abilities or traits, and to resist social pressures (Miller, 1988). Consequently, individuals in the United States and other individualist cultures are likely to construct a well-elaborated and accessible independent self-construal (Markus \& Kitayama, 1991; Triandis, 1989). In this self-construal, the individual is represented as a bounded entity, separate from relationships or group memberships; the principal components of this self-construal are enduring characteristics such as the individual's important traits, abilities, preferences, or attitudes (Cousins, 1989; Geertz, 1973; Shweder \& Bourne, 1984). Many processes and concepts related to the self in contemporary research in social and personality psychology are a product of the distinctive features of the independent self-construal. For example, beliefs in the value of uniqueness and individuality underlie the false uniqueness effect (Marks, 1984) and the processes identified in Tesser's (1988) self-evaluation maintenance theory.

\section{COLLECTIVISM AND THE INTERDEPENDENT SELF-CONSTRUAL}

Members of collectivist societies tend to define the self primarily by referring to aspects of their social roles and memberships and to the inextricable relatedness of the individual to others (Cousins, 1989; Hofstede, 1980; Markus \& Kitayama, 1991; Triandis, 1989; Triandis, Bontempo, Villareal, Asai, \& Lucca, 1988). As a result, members of collectivist cultures are likely 
to elaborate the interdependent self-construal, in which the principal components are one's relationships with important others and in-groups (Markus \& Kitayama, 1991; Triandis, 1989). Markus and Kitayama (1991) suggest that the normative tasks of individuals with an interdependent self-construal are to fit into relationships and to pursue a sense of belonging with others. To pursue harmony in these relationships, one attempts to meet the needs of others and to promote group goals; therefore, an individual's thoughts, feelings, and behaviors are largely a function of his or her relationships with others and group memberships.

This is not to say that the person with an interdependent self-construal has no conception of internal traits, characteristics, or preferences that are unique to him or her; instead, these internal, private aspects of the self are not primary in directing or guiding behavior in many situations in collectivist cultures. In most matters of social behavior in these societies, the internal, private, or independent aspect of the self is subordinate to the collective or interdependent component of the self (Bachnik, 1992; Hsu, 1971; Rosenberger, 1989; Triandis, 1989; Wu, 1984; Yamaguchi, Kuhlman, \& Sugimori, 1995).

\section{SELF-CONSTRUAL AND COPING}

These cultural differences in the self-system challenge much current thinking about cognition, emotion, and behavior. For example, the preferred strategies of personal control and coping may vary with the nature of the self-construal. In an insightful integration of Japanese and American research, Weisz et al. (1984) argue that the control attempts of individuals from collectivist cultures differ importantly from those of members of individualist cultures. They suggest that in individualist cultures, where uniqueness and self-expression are stressed, taking direct action, confronting others, or speaking up in one's own behalf are the normative, preferred means of addressing a problem or difficulty. They label these direct attempts to influence the existing situation through the individual's own efforts primary control strategies; the term direct is substituted in discussion of primary coping strategies in this article (see also Rothbaum, Weisz, \& Snyder, 1982). ${ }^{1}$

Individuals with an interdependent self-construal, who prefer close alignment or harmony with others, attempt to adjust to social situations through strategies that focus on changing the self rather than changing the situation (Weisz et al., 1984; Yang, 1986; see also Bond, Wan, Leung, \& Giacalone, 1985; Hwang, 1978, reported in Bond \& Hwang, 1986). Examples of these indirect strategies include reinterpreting a situation so as to derive meaning from it, accepting the situation and changing one's own expectations or desires, or vicariously experiencing control by closely identifying with a 
more powerful other. Weisz et al. (1984) label these indirect attempts to regulate the self and psychological responses to a situation secondary control strategies. In collectivist cultures, in which individual wishes and goals are subordinated to group goals, direct coping strategies may be viewed as immature or selfish and can threaten harmony in relationships.

Although secondary or indirect coping strategies may be adaptive or effective in a collectivistic culture, they may be ineffective when an international student employs them in an individualistic culture that values and rewards direct coping strategies. The well-being of the international student from a collectivist culture may in some part depend on learning and using these direct coping strategies. For example, obtaining attention from faculty, financial support, or recognition of one's work often requires putting oneself forward, distinguishing oneself from others, or speaking out in one's own behalf (Sandler \& Hall, 1986; Triandis, Brislin, \& Hui, 1988; Widnall, 1988). In this study, I hypothesized that East Asian students' self-construals and use of direct coping strategies would predict adjustment to graduate school in the United States.

\section{ADJUSTMENT TO A NEW CULTURE}

\section{PREVIOUS RESEARCH ON INTERNATIONAL STUDENTS' ADJUSTMENT}

These self-construals and their cognitive, emotional, and behavioral consequences are products of particular cultural environments. But what happens

when one enters a dramatically different culture? Immersion in a new culture often challenges one's beliefs, values, self-view, and worldview. The newcomer is confronted by new information and patterns of behavior and must learn different ways of thinking and behaving. As a result of these and other consequences of culture change (e.g., language difficulties, loss of similar friends and family, and the need to learn appropriate new social skills and academic behaviors), the international student may experience psychological stress or "culture shock" (Bourne, 1975; Furnham, 1988; Guthrie, 1979; Huang, 1977; Kim \& Gundykunst, 1988; Oberg, 1960; for reviews of the culture shock literature, see Barna, 1983; Berry, Kim, Minde, \& Mok, 1987; Furnham \& Bochner, 1986; Stening, 1979).

To evaluate the impact of self-construals and direct coping on crosscultural adjustment, one must take into account other variables that have been related to this process. The existing research is often contradictory or inconclusive with regard to determining who adjusts well to this culture; factors such as gender, age, marital status, housing arrangements, financial support, language ability, and previous experience in other cultures often predict 
international student adjustment (Armes \& Ward, 1989; Church, 1982; Furnham \& Bochner, 1986; Hull, 1978; Kealey, 1989; Searle \& Ward, 1990; Spaulding \& Flack, 1976; Ward \& Kennedy, 1992).

Two factors-relationships with others from one's home country and friendships with host country nationals-predict adjustment in many studies (Furnham, 1988). Enclaves of conationals are common among Asian student groups in the United States; they provide the student with friendships, a reference group, and support for his or her cultural identity and values (Adelman, 1988; Berry et al., 1987; Bochner, 1986; Bochner, McLeod, \& Lin, 1977; Boyer \& Sedlacek, 1988; Furnham \& Alibhai, 1985). Social support has also been found to be a critical influence in depression and stress (Cohen \& Wills, 1985; Leavy, 1983; Lin, Simeone, Ensel, \& Kuo, 1979). However, maintaining supportive relationships with others from one's country may require behaving interdependently; a student who is very independent or "Americanized" may be ostracized from groups of conationals.

These enclaves of conationals sometimes restrict the student's interactions with students from the host culture. Relationships with host nationals have predicted successful adjustment for international students in many studies (Church, 1982; Furnham, 1988; Hammer, 1987; Kealey, 1989; Klein et al., 1971; Kleinberg \& Hull, 1979; Searle \& Ward, 1990; Ward \& Kennedy, 1993; Yao, 1983). It is generally believed that friendships with host country nationals provide international students with opportunities to learn more about the culture, to gain practical information, and to develop social skills, but few researchers have delved further to attempt to discover who is likely to develop these relationships (Furnham \& Alibhai, 1985).

However, developing friendships with Americans may be difficult for some East Asian students. Triandis (1989) argues that in collectivist cultures, individuals belong to a few stable in-groups and have intense relationships within those in-groups. Americans, by contrast, belong to many in-groups; in-group membership is viewed as voluntary, and responsibilities and attachments to most others within those groups are less intense than they are in collectivist cultures. (See Triandis, 1989, for an explanation of the antecedents of these differences.) The visiting student who values interdependence may be dissatisfied with Americans' apparently superficial friendships and may therefore avoid developing friendships with American students. By contrast, international students who think of themselves as independent may perceive more similarity between themselves and American colleagues and therefore may be more likely to seek out American friends (Byrne, 1971). Consequently, this study also examines the association between self-construals and relationships with others from the sojourner's home country as well as relationships with host country nationals. 


\section{OVERVIEW OF THIS STUDY}

To examine the role of the independent and interdependent self-construals in cross-cultural adjustment, this study focused on students from countries that all share Confucianism as a primary philosophical tradition (the People's Republic of China [PRC], South Korea, Taiwan, and Japan) who were beginning graduate studies in the United States (Hofstede, 1991; Tu, 1985). They were matched with a sample of American students who were also beginning graduate school.

In this study, as in some others (Trafimow, Triandis, \& Goto, 1991; Triandis, 1989; see also Greenwald \& Breckler, 1985), the interdependent and independent self-construals were represented as two components of the self-concept (Bontempo, 1993). An assumption here was that the interdependent self-construals of most individuals from East Asian countries are very well elaborated and frequently direct thought, emotion, and behavior, whereas American students' independent self-construals are well elaborated and active in memory (Doi, 1986; Lebra, 1976; Markus \& Kitayama, 1991; Triandis, 1989; Triandis, Brislin, \& Hui, 1988). Therefore, I expected to find differences in the importance of these self-construals between American and East Asian students. However, the international students who choose to leave friends and family and venture abroad may be more likely to view themselves as particularly independent or individualistic than are students who do not choose to study abroad.

I predicted that the independent and interdependent self-construals would influence the perceived stress of the international students indirectly by affecting their coping strategies and relationships with others. Self-construals were also expected to have a direct effect on well-being; a lack of fit between one's self-construals and cultural norms may contribute to stress and tension (Caplan, 1983; Niedenthal, Cantor, \& Kihlstrom, 1985; Searle \& Ward, 1990). Therefore, the direct and indirect effects of the independent and interdependent self-construals were assessed using path analysis. Other previously identified predictors of stress for international students such as age, gender, marital status, housing arrangements, and language ability were also controlled in this path analysis.

\section{METHOD}

\section{RESPONDENTS}

The present analyses are based on data collected during the respondents' first year of graduate school. The results reported here were part of a larger 
longitudinal project (Cross, 1990). The graduate school at the University of Michigan granted permission to survey entering East Asian and domestic students; it also provided student names, addresses, and assistance in sending out the questionnaires. The international student sample consisted of all entering students from South Korea, Taiwan, the PRC, and Japan. Domestic subjects were matched to the international student sample by gender and department (all naturalized immigrants were excluded). Where matches by department were not available, American students were selected from a related department.

The original sample of international students consisted of 99 Taiwanese students ( 27 females and 72 males), 49 Korean students ( 9 females and 40 males), 54 students from the PRC ( 14 females and 40 males), and 18 Japanese students (6 females and 12 males) for a total sample of 220 international students. Of this original sample, $7.3 \%(n=16)$ were enrolled in the social sciences; $11.4 \%(n=25)$ were enrolled in the humanities; $50.5 \%(n=111)$ were enrolled in engineering and related fields; $15.9 \%(n=35)$ were enrolled in the natural sciences; $5 \%(n=11)$ were enrolled in medicine, nursing, or related fields; $3.6 \%(n=8)$ were enrolled in art, architecture, or music; $1.8 \%$ $(n=4)$ were enrolled in business; $2.7 \%(n=6)$ were enrolled in education, and $1.8 \%(n=4)$ were enrolled in other fields or in interdisciplinary programs. As mentioned earlier, the American sample matched this group by gender and department.

\section{PROCEDURE}

The questionnaires were mailed to the students' homes during mid-March of their first year of graduate school. When students' home addresses were not available, the questionnaires were sent through campus mail to their departmental addresses on campus. Respondents were given prepaid envelopes so that the questionnaires could be returned directly through the U.S. Postal Service. A follow-up card was sent to all the students after 3 weeks, and an attempt was made by phone to contact students who had not returned the questionnaire after 1 month.

From the initial sample of international students, five questionnaires either were returned as undeliverable or were marked that the student had withdrawn from the university. Six of the questionnaires sent to American students also were undeliverable. These figures may not reflect the true number of questionnaires that were not received by students; it is difficult to calculate the reliability of the campus mail service and departmental staff. Of the remaining students assumed to have received the questionnaire, $32.3 \%(n=$ 
TABLE 1

Demographics of the East Asian and

American Samples (percentages)

\begin{tabular}{lcc}
\hline \hline Variable & $\begin{array}{c}\text { Asian Students } \\
(\mathrm{n}=71)\end{array}$ & $\begin{array}{c}\text { American Students } \\
(\mathrm{n}=79)\end{array}$ \\
\hline Nationality & & \\
Korean & 18.3 & \\
Taiwanese & 54.9 & \\
Chinese & 21.1 & \\
Japanese & 5.6 & \\
Gender & & 74.7 \\
Male & 73.2 & 25.3 \\
Female & 26.8 & \\
Marital status & & 35.4 \\
Married & 32.4 & 58.2 \\
Single & 57.8 & 6.3 \\
Other & 9.9 & \\
Department & & 7.6 \\
Social sciences, education & 7.0 & 15.2 \\
Humanities & 15.5 & 57.0 \\
Engineering & 56.3 & 10.1 \\
Natural sciences & 12.7 & 5.1 \\
Medicine, public health & 2.8 & 2.5 \\
Art, music, architecture & 2.8 & 2.5 \\
Business & 1.4 & 0 \\
Other & 1.4 & \\
\hline
\end{tabular}

71) of the East Asian students and 35.9\% $(n=79)$ of the American sample returned the instrument. Table 1 presents the demographics of the sample and shows that the characteristics of the two groups (gender, marital status, and department) were nearly identical.

\section{INSTRUMENT}

Measures of the self-construals, coping styles, social support, and psychological well-being were included in a questionnaire for this study. The cover letter described the project as a "study examining graduate students' adjustment." Students were informed of the graduate school's participation and were assured that all replies would be kept strictly confidential. This questionnaire required less than 45 minutes to complete. 


\section{Independence and Interdependence}

The Private Ego-Task subscale from the Breckler, Greenwald, and Wiggins (1986) Ego-Tasks Subscales was selected to measure the independent selfconstrual. Greenwald and Breckler's (1985) work on ego-tasks (also see Breckler \& Greenwald, 1986) was also related to collectivism and individualism by Triandis (1989). Breckler and his colleagues report that the Private Ego-Task subscale had acceptable internal consistency (alpha $=.59$ using a sample of American college students) and good construct validity.

Items from a measure of group-oriented collectivism (Yamaguchi, 1990, 1994) were used to assess the interdependent self-construal. Yamaguchi (1990) added these latter items to Breckler et al.'s (1986) original set based on his work with Japanese subjects. Yamaguchi (1994) and Yamaguchi et al. (1995) report that in research with Japanese students, the Collectivism Scale had high internal reliability (Cronbach's alpha ranged from .77 to .88 ) and good test-retest reliability over 3 months $(r=.71)$ (Yamaguchi, 1990). It was found to be free from acquiescence and social desirability biases. In a recent study, Yamaguchi and his colleagues (1995) found similar reliabilities using Korean students (alpha $=.71$ ) and American students (alphas ranged from .69 to .72$)$.

Instructions for completing the independent and interdependent selfconstrual items read as follows:

Each of the following phrases describes some characteristic of a person. We would like for you to rate the importance of each statement for yourself. Some of the statements may be something you regard as very important to you, while others may not be very important to you. Please indicate next to each phrase how important each of the following statements are for you now using the scale below.

Sample items included "being unique-different from others in many respects" and "maintaining harmony in one's group." The items used in this study are presented in the Appendix. Respondents indicated the importance of each statement by responding with a 6-point scale $(1=$ not at all important, $6=$ extremely important), and responses were averaged to form two scales. The alphas for the East Asian students were .72 (independent self-construal) and .78 (interdependent self-construal). The alphas for the American students were .62 (independent) and .68 (interdependent). These reliabilities, although lower than might be desired, are comparable with those reported in other studies of individualism and collectivism such as Singelis (1994) and Triandis, Leung, Villareal, and Clack (1985). Responses to self-construal measures like these may be more sensitive than other traditional trait measures to the individual's frame of reference when answering the questions. Given the highly contextualized or relationship-specific nature of the interdependent 
self-construal, respondents may have in mind a variety of groups or situations when answering these questions. They may also think about different groups or situations when completing these measures at two different times. This can result in greater variability in responses and lower levels of reliability than one finds in other measures. ${ }^{2}$

\section{Direct Coping}

Direct coping was measured using items from the Carver, Scheier, and Weintraub (1989) COPE Scale, which assesses a wide variety of coping responses. In constructing the questionnaire, only two items were chosen from each of 11 COPE subscales to keep the questionnaire short. Only the items that were easily translated (i.e., did not include difficult to translate idioms or slang) and that loaded the most heavily on each factor were chosen. Because the Active Coping and Planning subscales of the COPE Scale most closely related to the concept of primary or direct coping, the items from those subscales were averaged to form a single direct coping measure for this study.

Respondents were given the following instructions for completing this section of the instrument:

We would like for you to think about a stressful event that happened to you that was related to school. Perhaps it had to do with a class, a grade, or some other aspect of your schoolwork. Please briefly describe the event you are thinking about in the space below. Using your own words, please describe what happened, where it happened, and who was involved.

With this situation in mind, they were to indicate how often they engaged in each coping strategy using a 4-point scale ( $1=I$ didn't do this at all, $4=I$ did this a lot). The items used in the Direct Coping measure were as follows:

I take additional action to try to get rid of the problem.

I concentrate my efforts on doing something about it.

I try to come up with a strategy about what to do.

I make a plan of action.

The East Asian students' average scores $(M=3.25, S D=.67)$ were very similar to the American students' scores $(M=3.28, S D=.64), t(131)<1.0$. Cronbach's alphas were .76 for the East Asian students and .78 for the American students.

\section{Satisfaction Measures}

Several items that asked respondents to indicate how satisfied they were with various aspects of their graduate experience were included in the 
instrument. This study focused on questions addressing aspects of students' relationships. A measure of satisfaction with relationships with conationals (for the East Asian students) was created by averaging responses to the questions "How satisfied are you with your social relationships with other students from your country?" and "How satisfied are you with your schoolrelated relationships with other students from your country?" Students responded with a 6 -point scale $(1=$ not at all satisfied, $6=$ very satisfied $)$.

The American students were asked "How satisfied are you with your social relationships with other students?" and "How satisfied are you with your school-related relationships with other students?"3

East Asian students' relationships with host country nationals were assessed with the question, "How many American friends do you have with whom you can discuss personal problems?"

\section{Language Ability}

To create the measure of perceived English ability, international students were asked to rate themselves on the following items using a 6-point scale $(1=$ very poor, $6=$ extremely good):

How good are you at understanding spoken English?

Please rate your English conversation ability.

Please rate your ability to participate in class discussions.

Please rate your ability to write papers in English.

\section{Background Data}

At the end of the instrument, respondents were asked for background information such as their age, marital status, gender, housing arrangements (whether they lived on or off campus), citizenship, previous international travel, and satisfaction with financial support. ${ }^{4}$ Questions that were inappropriate for American students were either reworded or eliminated from the questionnaire.

\section{Perceived Stress}

Ten items from the Perceived Stress Scale (PSS; Cohen, Kamarck, \& Mermelstein, 1983) were included to measure psychological well-being. This scale measures respondents' appraisals of the stressfulness of their current life situations in fairly global terms. Cohen and his colleagues have found that the PSS has high test-retest reliability (.85 over a 2-week period) and is a significant predictor of outcomes such as depression, social anxiety, and 
illness. They reported coefficient alpha reliabilities ranging from .84 to .86 for the scale. Two items were not included in this study after consultation with translators who found colloquial language to be problematic ("How often have you felt that you were on top of things?" and "How often have you felt that things were going your way?"). Two items that were inconsistent with East Asian views of responding to stressful events also were dropped ("How often have you been angered because of things that happened that were out of your control?" and "How often have you found yourself thinking of things that you have accomplished?"). (These items also had very small correlations with the other items in the scale for the East Asian sample.) Respondents were asked to respond to each statement with one of the following alternatives:

1. rarely or none of the time;

2. some or a little of the time;

3. occasionally or a moderate amount of the time; or

4. most or all of the time.

The alphas for this scale were .68 for the East Asian students and .67 for the American students.

\section{TRANSLATION}

The questions were translated into Chinese, Japanese, or Korean by bilingual assistants. These were then back translated by other assistants to ensure equivalence of meaning (Brislin, 1986). When any of the translators had difficulty with an item, that item was deleted from the instrument. Five versions of the questionnaire were created (English, Korean, Japanese, and two versions of Chinese); for the international students, the questions were presented in both their home language (or script) and English.

\section{RESULTS}

\section{INDEPENDENT AND INTERDEPENDENT SELF-CONSTRUALS}

I expected American and East Asian students to differ in their ratings of the independent and interdependent self-construals. As Figure 1 illustrates, the groups' average scores did not differ significantly on the independent self-construal $(M$ [East Asians] $=4.85, S D=.63 ; M$ [Americans] $=4.89, S D=$ $.62), t(148)<1.0$. However, the East Asian respondents' average ratings of 
the importance of the interdependent self-construals items were much higher $(M=4.03, S D=.77)$ than the American respondents' ratings $(M=3.4, S D=$ $.78), t(144)=4.88, p<.001$. Tests of the equality of variances showed no differences between the groups on these scales. This suggests that the East Asian students were not more likely to restrict their responses to the middle of the scale, as other studies have found (Triandis, Bontempo, Villareal, Asai, \& Lucca, 1988). In addition, these two scales were not correlated with each other in either group ( $r=.02$ for the East Asians and $r=-.07$ for the American respondents), indicating that these measures represent two unrelated components of the self. This finding may seem counterintuitive; however, as Triandis and others have discussed, individuals in both individualist and collectivist cultures develop aspects of both self-construals (Lebra, 1976; Singelis, 1994; Trafimow et al., 1991; Triandis, 1989). Differing cultural norms and values influence the elaborateness or importance of each selfconstrual and prescribe which component of the self should direct behavior in various situations.

\section{PERCEIVED STRESS}

A foreign visitor in any country is subject to stressors that natives never experience, such as language difficulties, new norms and social customs, and challenges to one's self-views and beliefs. This was reflected in differences in the scores of the two groups on the PSS. After 7 months of graduate school in the United States, the East Asian students indicated that they were experiencing more stress $(M=2.24, S D=.46)$ than were the American students $(M=$ $2.05, S D=.48), t(142)=2.40, p<.01$, one-tailed. Tests of the equality of variances showed no differences between the groups on this scale.

\section{EFFECTS OF THE SELF-CONSTRUALS ON PERCEIVED STRESS}

The relationships between the self-construals and stress were examined with path analysis (Alwin \& Hauser, 1975; Asher, 1983). First, the variables measuring direct coping, satisfaction with relationships with conationals, and number of American friends were regressed on the self-construal scores; these were the hypothesized indirect paths linking the self-construals to perceived stress. Then perceived stress was regressed on the complete set of variables, including the background variables. These background variables were age, gender, marital status, number of countries the person had visited, whether one lived on or off campus, degree of satisfaction with one's financial support, and perceived English-language ability. Other background variables that have been mentioned in the literature were dropped from the analyses 


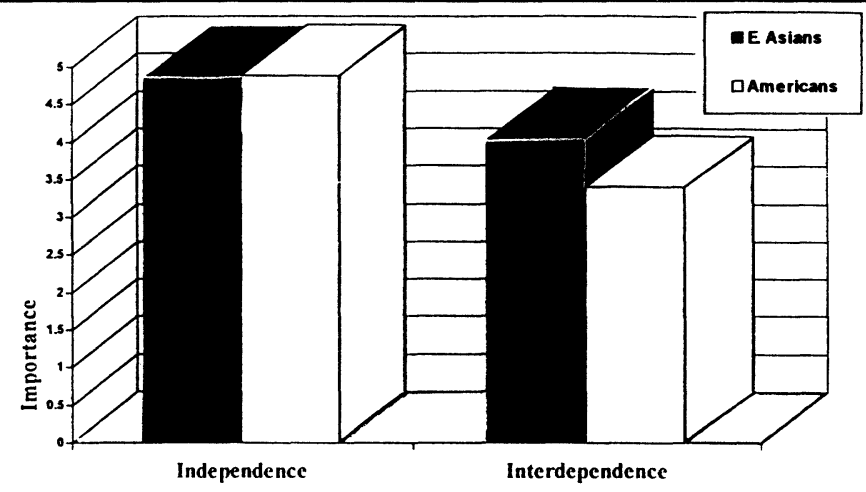

Figure 1: Differences in Self-Construals Between East Asian and American Graduate Students

when they did not relate significantly to perceived stress. These included students' Test of English as a Foreign Language scores, their academic departments, and a measure of how they were supported financially. Three subjects with missing data for the self-construal measures and the direct coping scale were eliminated from these analyses; however, to use as many cases as possible, all the regressions included group mean values for missing data on the other predictors.

\section{East Asian Students}

Figure 2 shows that the self-construals significantly influenced perceived stress for the international students. The international students who scored high on the importance of the independent self-construal made more direct attempts and plans to solve stressful events $(\beta=.45, p<.001)$, and this in turn reduced their levels of perceived stress $(\beta=-.38, p<.03)$. So direct coping substantially mediated the effect of the independent self-construal on perceived stress.

The interdependent self-construal had a positive direct effect on stress; students who described themselves as very interdependent also reported higher levels of stress, $\beta=.38, p<.01$. The interdependent self-construal did not predict direct coping or the number of close American friends. Neither of the self-construal scores was significantly related to the international students' satisfaction with their relationships with conationals, and neither of the relationship variables predicted perceived stress.

As the path analysis shows, the self-construals and direct coping were more important predictors of stress than was a model based on demographic or background variables identified by previous research (e.g., satisfaction 


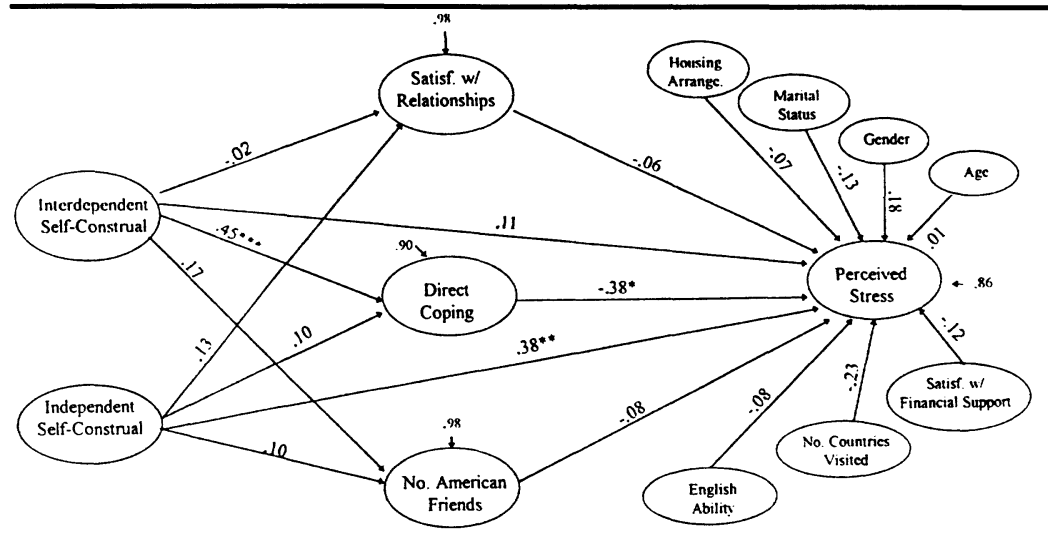

Figure 2: Path Analysis of the Variables Predicting Perceived Stress in East Asian Students

${ }^{*} p<.10,{ }^{* *} p<.05 ;{ }^{* * *} p<.01$.

with one's relationships with conationals and with Americans, perceived English ability, satisfaction with one's financial support, age, gender, marital status, and housing). A comparison of the variance explained by the partial model that included only these background variables and the full model (which added the variables for the independent and interdependent selfconstruals and direct coping) showed that the partial model did not predict perceived stress adequately, $R^{2}=.10, F(9,51)=.63$, n.s. Hierarchical regression analysis showed that the inclusion of the self-construal scores and the coping scale increased the variance explained by the equation significantly, $\Delta R^{2}=18, F(3,48)=4.00, p<.02$. The $R^{2}$ for the full equation predicting perceived stress was $.28, F(12,48)=1.55, p<.15$; the adjusted $R^{2}$ was .10.

Additional analyses were conducted to test for interactions between country of origin and the self-construals and direct coping in this path analysis. Based on scores on the interdependent and independent self-construal measures (see Table 2), the students from Taiwan and the PRC were grouped together and the students from Japan and Korea were grouped together.

A dummy variable was created to represent this grouping of the East Asian students. A hierarchical regression analysis was conducted; it included (in this order) all the variables in the original path analysis, the dummy variable for the East Asian groups, and the interaction terms for the East Asian groups and the self-construal and direct coping scores. This analysis revealed no main effect of country of origin for the East Asian students, nor did it reveal any significant interactions with the primary predictor variables. Although there are certainly many differences between these groups that are of neces- 
TABLE 2

Means of the Independent and Interdependent

Self-Construal Scores, by Country of Origin (East Asian students)

\begin{tabular}{lcccc}
\hline \hline Self-Construal Measure & $\begin{array}{c}\text { Taiwan } \\
(\mathrm{n}=37)\end{array}$ & $\begin{array}{c}P R C \\
(\mathrm{n}=15)\end{array}$ & $\begin{array}{c}\text { Korea } \\
(\mathrm{n}=12)\end{array}$ & $\begin{array}{c}\text { Japan } \\
(\mathrm{n}=4)\end{array}$ \\
\hline Independent & 4.80 & 4.80 & 5.00 & 5.08 \\
Interdependent & 4.03 & 3.67 & 4.30 & 4.55 \\
\hline
\end{tabular}

NOTE: PRC = People's Republic of China.

sity overlooked in these analyses, these results indicate that the relations between self-construals, coping, and stress for students studying in the United States are similar across these groups.

\section{American Students}

As Figure 3 illustrates, the most important predictor of perceived stress was the American students' satisfaction with their relationships. (The variables measuring perceived English-language ability and satisfaction with American friends were dropped from the equation for the American respondents.) American students who were content with their relationships with their peers reported less stress than did dissatisfied students during the first year of graduate school, $\beta=-.37, p<.01$. Comparisons of the American and East Asian students' scores on this predictor showed that Americans reported less satisfaction with their relationships $(M=3.9, S D=1.16)$ than did the East Asian students $(M=4.3, S D=1.00), t(129)=2.13, p<.04$, two-tailed.

American women in graduate school reported greater stress than did American men, $\beta=.24, p<.07$. Means on the PSS were 2.0 for the men and 2.2 for the women, $t(76)=1.68, p<.05$, one-tailed. Women in this group rated the importance of the interdependent self-construal lower than did men $(M=3.1$ for women and 3.5 for men, $t[76]=1.98, p=.05$, two-tailed), but there were no other significant differences between American men and women on the primary predictor variables (e.g., the independent selfconstrual, direct coping, or satisfaction with relationships).

The variance in perceived stress explained by the partial model (excluding the self-construal variables and direct coping) was .23, $F(7,62)=2.63, p<$ .03 (adjusted $R^{2}=.14$ ). The additional variables did not contribute significantly to the variance explained by this model, $\Delta R^{2}=.01$, n.s. The $R^{2}$ for the full equation predicting perceived stress was $.24, F(10,59)=1.90, p<.07$; the adjusted $R^{2}$ was .11. (This compares with an $R^{2}$ of .27 [adjusted $R^{2}=.12$ ] 


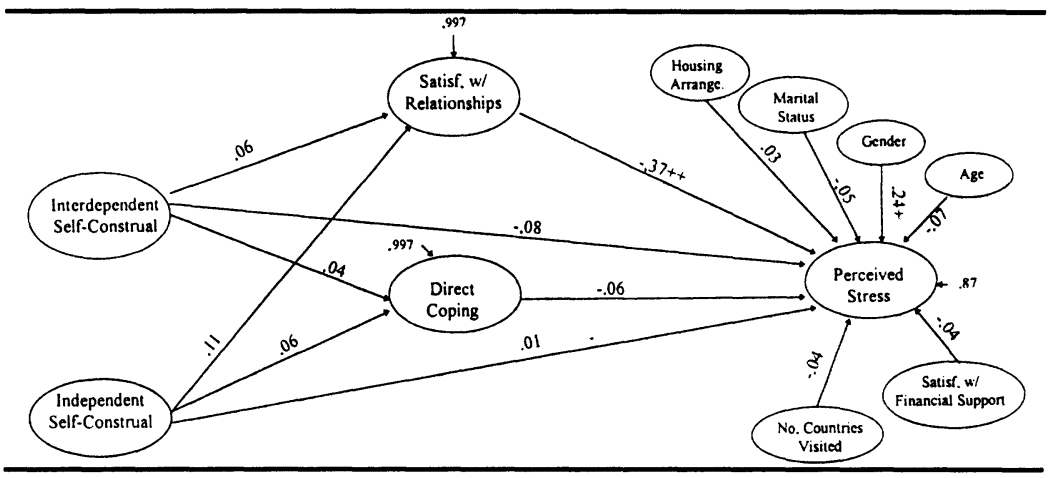

Figure 3: Path Analysis of the Variables Predicting Perceived Stress in American Students $+p<.10 ;{ }^{*} p<.05 ;{ }^{* *} p<.01$.

for the East Asian students when the variables for number of American friends and English ability were deleted from the equation.)

Tests of the differences in the path coefficients between the groups revealed that the relationship between the independent self-construal and direct coping for the East Asian students $(b=.46)$ was significantly different from the path coefficient for the American students $(b=.04), z=2.5, p<.05$. No other comparisons of the paths revealed significant differences between the groups.

\section{DISCUSSION}

This study examines cultural differences in self-construals and attests to the importance of the self in cross-cultural adaptation. As predicted, East Asian students in their first year of graduate school in the United States placed much more importance on the interdependent self-construal than did American students. However, the importance of the independent self-construal did not differ between the groups. This mirrors the findings of Triandis, McCusker, and Hui (1990) and Christopher (1992), who also found that Asian and American subjects scored similarly on measures of self-reliance or independence. Triandis et al. (1990) speculate that high scores on their measure of self-reliance (which may be considered a facet of the independent selfconstrual) may be due to modernization pressures in many East Asian countries. In this study, this finding may be a consequence of self-selection by the East Asian students. International students who choose to relocate to the United States to study may be more individualistic than those who stay at home. The difference in the ratings of the interdependent self-construal 
between the two groups represents differing perspectives on the relationship of the individual to the group. For Americans, expressing oneself and being autonomous often take priority over collective or group-oriented concerns (e.g., the American student working in a group may think first about what is best for himself or herself and then decide what is best for the group). By contrast, East Asians encourage self-reliance so that one may not be a burden on the group and to further group goals (Lebra, 1976; Markus \& Kitayama, 1991; Rosenberger, 1989; Triandis, 1989; Triandis, Bontempo, Villareal, Asai, \& Lucca, 1988).

This study demonstrates that self-construals importantly influence crosscultural adjustment. When the background variables that have been found to relate to international students' well-being were controlled, East Asian students who scored high on the interdependent self-construal measure reported high levels of stress. This effect may be mediated by many processes that are beyond the scope of this study. For example, the interdependent self-construal represents an array of beliefs about the person and society that are often challenged in American culture (e.g., "It is selfish to put one's own needs before the good of the group"). In addition, the very individualist American classroom, in which standing out and demonstrating one's uniqueness may be necessary for success, may prove frustrating for students with very interdependent self-views.

East Asian students who placed more importance on the independent self-construal used more direct coping strategies when addressing problems related to school. These strategies were in turn strongly related to reduced levels of perceived stress. Although the specific problems and steps taken to resolve the problems were left unstated in this study, these results suggest that students who were willing to stand out or to take direct action when problems arose in the classroom were less distressed.

The self-construals and direct coping scores were the strongest predictors of stress for international students. Several other factors that previously have been identified as predicting adjustment, such as number of American friends, relationships with others from one's home country, language ability, or previous foreign travel, did not significantly predict perceived stress in this model. This is contrary to findings by others; for example, Furnham (1988) argues that the evidence that factors such as contact with host country nationals predict cross-cultural adjustment supports the social skills learning approach. Advocates of this approach argue that individuals who master the necessary social skills and practices of the host country are more likely to adjust successfully. These results suggest some modification of the social skills approach. Perhaps social skills predict sociocultural adjustment (i.e., the ability to competently complete the tasks required in the new culture) 
rather than psychological adjustment (i.e., perceived stress or well-being) (Searle \& Ward, 1990). For some sojourners, behaving appropriately in a given situation may require behaviors that are inconsistent with their own self-views. As a result, they may have difficulty learning these new social skills and generalizing them beyond training or practice situations (Zaharna, 1989). Indeed, the nature of the self-concept may influence the degree to which a sojourner will develop and employ appropriate social skills.

The effect of self-construals and coping on stress was moderated by culture. For American students, the self-construal scores were not significant predictors of perceived stress. Because Americans are not undergoing a radical culture change, the interdependent and independent self-construals may not be significantly related to well-being in this situation. These measures also had a somewhat lower internal reliability for the American students, and this may be a factor in their lower predictiveness in this model. The strongest predictor of perceived stress for American students, satisfaction with relationships, did not predict Asian students' stress. The questions composing this index may require a stance or perspective that is uncomfortable or unfamiliar to East Asian students. Answering the question "How satisfied are you with your relationships with other students from your country?" requires that the individual cognitively separate himself or herself from the group to make a judgment. If the self-concept of the East Asian student is largely created and defined by relationships with close others and in-groups, then to step away from that group to evaluate one's satisfaction with it may be a stance that is not taken easily or willingly. ${ }^{5}$ In addition, relationships with others from one's home country may be viewed as obligatory for the East Asian student; consequently, one's level of satisfaction with those relationships may be seen as irrelevant in comparison to the responsibilities and duties of a group member (Shweder \& Bourne, 1984; Wheeler, Reis, \& Bond, 1989). Future research will profit from a focus on other dimensions of relationships with conationals, such as types of instrumental support provided or frequency of contact.

\section{LIMITATIONS OF THIS STUDY}

Measures of self-construals and coping strategies that are valid and reliable for both American and East Asian students are still in development. As a result, many researchers use instruments developed for use with EuroAmerican populations. This study deliberately employed a measure of the interdependent self-construal that was created with reference to the Japanese perspective on the self (Yamaguchi, 1990, 1994). This solution to the mea- 
surement problem is practical but far from ideal. Low reliabilities of the self-construal measures in this study may have resulted in the underestimation of the strength of the relationships examined in the path analysis. Rather than letting this and other measurement difficulties impede research, investigators should acknowledge these limitations and anticipate continued improvements in the available measures. As interest in collective or interdependent perspectives on the self grows among researchers (e.g., Aron, Aron, Tudor, \& Nelson, 1991; Crocker \& Luhtanen, 1990; Markus \& Cross, 1990; Singelis, 1994), collaborative efforts between researchers from different cultural backgrounds will facilitate the development of instruments that can enrich cross-cultural research.

One may also question the direction of the relationship between the self-construal, coping strategies, and stress assumed here. An alternative interpretation might suggest that international students who are under great stress engage in compensatory bolstering, inflating the importance of the interdependent self-construal (Steele, 1988). An international student who experiences a difficulty at school may think about himself or herself as a good group member and about how he or she may fit in to this situation. On the other hand, if one responds repeatedly to problematic experiences with direct or primary coping strategies, these self-perceptions of independence are likely to be internalized (Bem, 1967). As the individual comes to think of himself or herself as independent, the use of these direct coping strategies may seem easier and more natural and will subsequently facilitate adjustment. Of course, longitudinal studies are necessary to confirm these assumptions of causal direction and to further examine the influence of the self-concept on adjustment to a new culture.

\section{CONCLUSIONS}

One way of understanding these findings is in terms of "culture fit" (Searle \& Ward, 1990). In this study, East Asian students whose self-views and coping strategies were consistent with the culture's norms and ideals (i.e., independence and direct coping) experienced lower levels of perceived stress than did other East Asian students. Students whose self-views were discrepant with cultural values (i.e., interdependent) expressed high levels of perceived stress. Further exploration of the processes mediating a sense of fit between the sojourner's self-construals and the cultural values of the host country will help sojourners and scientists alike better understand adaptation to a new culture. 


\section{APPENDIX \\ Self-Construal Items}

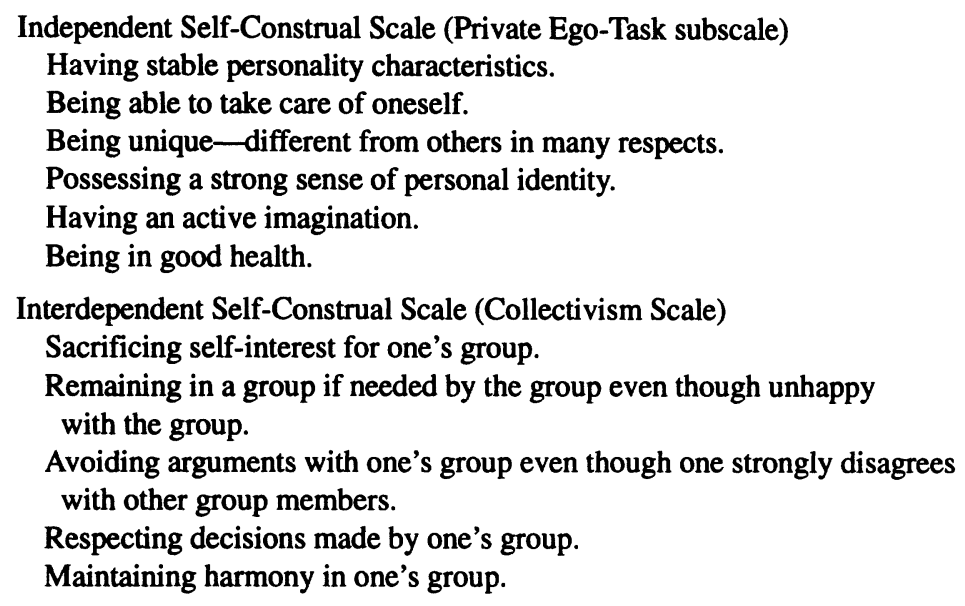

SOURCES: Breckler et al. (1986); Yamaguchi (1990).

\section{NOTES}

1. The term primary implies that these strategies are prior to or more important than other strategies one may select to exercise control. These strategies may only appear to be primary or most important from a Western, individualist perspective.

2. Thanks are due to Richard Brislin for his comments on this issue.

3. American students were also asked to indicate their satisfaction with their relationships with international students, but very few Americans reported spending any time with students from other countries. As a result, responses to these items were not included in the analyses.

4. In the analyses, gender was coded as 0 for males and 1 for females. In addition, dummy variables were created for marital status and housing arrangements. Students who were married and living with their spouses were coded as 1 , whereas single, divorced, or separated students were coded as 0 . Students living on campus were given the value 0 for the variable for housing arrangements, whereas those living off campus were given the value 1 .

5. I appreciate Hazel Markus's suggestion of this interpretation.

\section{REFERENCES}

Adelman, M. B. (1988). Cross-cultural adjustment: A theoretical perspective on social support. International Journal of Intercultural Relations, 12, 183-204.

Alwin, D. F., \& Hauser, R. M. (1975). The decomposition of effects in path analysis. American Sociological Review, 40, 37-47. 
Armes, K., \& Ward, C. (1989). Cross-cultural transitions and sojourner adjustment in Singapore. Journal of Social Psychology, 129, 273-275.

Aron, A., Aron, E. N., Tudor, M., \& Nelson, G. (1991). Close relationships as including other in the self. Journal of Personality and Social Psychology, 60, 241-253.

Asher, H. B. (1983). Causal modeling. Beverly Hills, CA: Sage.

Bachnik, J. M. (1992). The two "faces" of self and society in Japan. Ethos, 20, 3-32.

Barna, L. M. (1983). The stress factor in intercultural relations. In D. Landis \& R. W. Brislin (Eds.), Handbook of intercultural training (pp. 19-49). New York: Pergamon.

Baumeister R. (1987). How the self became a problem: A psychological review of historical research. Journal of Personality and Social Psychology, 52, 163-176.

Bem, D. (1967). Self-perception: An alternative interpretation of cognitive dissonance phenomena. Psychological Review, 74, 183-200.

Berry, J. W., Kim, U., Minde, T., \& Mok, D. (1987). Comparative studies of acculturative stress. International Migration Review, 21, 491-511.

Bochner, S. (1986). Coping with unfamiliar cultures: Adjustment or culture learning? Australian Journal of Psychology, 38, 347-358.

Bochner, S., McLeod, B. M., \& Lin, A. (1977). Friendship patterns of overseas students: A functional model. International Journal of Psychology, 12, 277-294.

Bond, M. H., \& Hwang, K. K. (1986). The social psychology of the Chinese people. In M. H. Bond (Ed.), Psychology of the Chinese people (pp. 213-266). Hong Kong: Oxford University Press.

Bond, M. H., Wan, K. C., Leung, K., \& Giacalone, R. (1985). How are responses to verbal insult related to cultural collectivism and power distance? Journal of Cross-Cultural Psychology, 16, 111-127.

Bontempo, R. (1993). Translation fidelity of psychological scales: An item response theory analysis of an individualism-collectivism scale. Journal of Cross-Cultural Psychology, 24, 149-166.

Bourne, P. G. (1975). The Chinese student: Acculturation and mental illness. Psychiatry, 38, 269-277.

Boyer, S. P., \& Sedlacek, W. E. (1988). Noncognitive predictors of academic success for international students: A longitudinal study. Journal of College Student Development, 29, 218-223.

Breckler, S. J., \& Greenwald, A. G. (1986). Motivational facets of the self. In R. M. Sorrentino \& E. T. Higgins (Eds.), Handbook of motivation and cognition: Foundations of social behavior (pp. 145-164). New York: Guilford.

Breckler, S. J., Greenwald, A. G., \& Wiggins, E. C. (1986, April). Public, private, and collective self-evaluation: Measurement of individual differences. Paper presented at the International Research and Exchanges Board conference on Self and Social Involvement, Princeton, NJ.

Brislin, R. W. (1986). The wording and translation of research instruments. In W. J. Lonner \& J. W. Berry (Eds.), Field methods in cross-cultural research (pp. 137-164). Beverly Hills, CA: Sage.

Byrne, D. (1971). The attraction paradigm. New York: Academic Press.

Caplan, R. D. (1983). Person-environment fit: Past, present, and future. In C. L. Cooper (Ed.), Stress research (pp. 35-78). New York: Wiley.

Carver, C. S., Scheier, M. F., \& Weintraub, J. K. (1989). Assessing coping strategies: A theoretically based approach. Journal of Personality and Social Psychology, 56, 267-283.

Christopher, J. C. (1992). The role of individualism in psychological well-being: Exploring the interplay of ideology, culture, and social science. Unpublished doctoral dissertation, University of Texas at Austin, Department of Educational Psychology.

Church, A. T. (1982). Sojourner adjustment. Psychological Bulletin, 91, 540-572. 
Cohen, S., Kamarck, T., \& Mermelstein, R. (1983). A global measure of perceived stress. Journal of Health and Social Behavior, 24, 385-396.

Cohen, S., \& Wills, T. A. (1985). Stress, social support and the buffering hypothesis. Psychological Bulletin, 98, 310-357.

Cousins, S. D. (1989). Culture and self-perception in Japan and the United States. Journal of Personality and Social Psychology, 56, 124-131.

Crocker, J., \& Luhtanen, R. (1990). Collective self-esteem and the ingroup bias. Journal of Personality and Social Psychology, 58, 60-67.

Cross, S. E. (1990). The role of the self-concept in cross-cultural adaptation. Unpublished doctoral dissertation, University of Michigan, Ann Arbor, Department of Psychology.

Doi, L. T. (1986). The anatomy of self. Tokyo: Kodansha.

Furnham, A. (1988). The adjustment of sojourners. In Y. Y. Kim \& W. B. Gundykunst (Eds.), Cross-cultural adaptation: Current approaches (pp. 42-61). Newbury Park, CA: Sage.

Furnham, A., \& Alibhai, N. (1985). The friendship networks of foreign students: A replication and extension of the functional model. International Journal of Psychology, 20, 709-722.

Furnham, A., \& Bochner, S. (1986). Culture shock: Psychological reactions to unfamiliar environments. New York: Methuen.

Geertz, C. (1973). The interpretation of cultures. New York: Basic Books.

Greenwald, A. G., \& Breckler, S. J. (1985). To whom is the self presented? In B. R. Schlenker (Ed.), The self and social life (pp. 126-145). New York: McGraw-Hill.

Greenwald, A. G., \& Praktanis, A. R. (1984). The self. In R. S. Wyer \& T. Srull (Eds.), Handbook of social cognition (Vol. 3, pp. 129-178). Hillsdale, NJ: Lawrence Erlbaum.

Guthrie, G. M. (1979). A cross-cultural odyssey: Some personal reflections. In A. J. Marsella, R. G. Tharp, \& T. J. Ciborowski (Eds.), Perspectives on cross-cultural psychology (pp. 349368). New York: Academic Press.

Hammer, M. R. (1987). Behavioral dimensions of intercultural effectiveness: A replication and extension. International Journal of Intercultural Relations, 11, 65-88.

Hofstede, G. (1980). Culture's consequences: International differences in work-related values. Beverly Hills, CA: Sage.

Hofstede, G. (1991). Cultures and organizations: Software of the mind. London: McGraw-Hill.

Hsu, F.L.K. (1971). Psycho-social homeostasis and jen: Conceptual tools for advancing psychological anthropology. American Anthropologist, 73, 23-44.

Huang, K. (1977). Campus mental health: The foreigner at your desk. Journal of the American College Health Association, 25, 216-219.

Hull, W. F. (1978). Foreign students in the United States of America: Coping behavior within the educational environment. New York: Praeger.

Hwang, K. K. (1978). The dynamic processes of coping with interpersonal conflicts in a Chinese society. Proceedings of the National Science Council, 2, 198-208.

Kealey, D. J. (1989). A study of cross-cultural effectiveness: Theoretical issues, practical applications. International Journal of Intercultural Relations, 13, 387-428.

Kim, Y. Y., \& Gundykunst, W. B. (1988). Cross-cultural adaptation: Current approaches. Newbury Park, CA: Sage.

Klein, M. H., Alexander, A. A., Tseng, K. H., Miller, M. H., Yeh, E. K., Chu, H. M., \& Workneh, F. (1971). The foreign student adaptation program: Social experiences of Asian students in the U.S. International Educational and Cultural Exchange, 6, 77-90.

Kleinberg, O., \& Hull, W. F. (1979). At a foreign university: An international study of adaptation and coping. New York: Praeger.

Leavy, R. L. (1983). Social support and psychological disorder: A review. Journal of Community Psychology, 11, 3-21. 
Lebra, K. S. (1976). Japanese patterns of behavior. Honolulu: University of Hawaii Press.

Lin, N., Simeone, R. S., Ensel, W. M., \& Kuo, W. (1979). Social support, stressful life events, and illness: A model and an empirical test. Journal of Health and Social Behavior, 25, 176-188.

Marks, G. (1984). Thinking one's abilities are unique and one's opinions are common. Personality and Social Psychology Bulletin, 2, 165-177.

Markus, H., \& Cross, S. E. (1990). The interpersonal self. In L. Pervin (Ed.), Handbook of personality theory and research (pp. 576-608). New York: Guilford.

Markus, H., \& Kitayama, S. (1991). Culture and the self: Implications for cognition, emotion, and behavior. Psychological Review, 98, 224-251.

Markus, H., \& Wurf, E. (1987). The dynamic self-concept: A social psychological perspective. Annual Review of Psychology, 38, 299-337.

Miller, J. G. (1988). Bridging the content-structure dichotomy: Culture and the self. In M. H. Bond (Ed.), The cross-cultural challenge to social psychology (pp. 266-281). Newbury Park, CA: Sage.

Niedenthal, P. M., Cantor, N., \& Kihlstrom, J. F. (1985). Prototype-matching: A strategy for social decision-making. Journal of Personality and Social Psychology, 48, 575-584.

Oberg, K. (1960). Culture shock: Adjustment to new cultural environments. Practical Anthropology, 7, 177-182.

Rosenberger, N. R. (1989). Dialectic balance in the polar model of self: The Japan case. Ethos, 17, 88-113.

Rothbaum, R., Weisz, J. R., \& Snyder, S. S. (1982). Changing the world and changing the self: A two-process model of perceived control. Journal of Personality and Social Psychology, 42, 5-37.

Sandler, B., \& Hall, R. (1986). The campus climate revisited: Chilly for women faculty, administrators, and graduate students. Washington, DC: Association of American Colleges, Project on the Status and Education of Women.

Searle, W., \& Ward, C. (1990). The prediction of psychological and sociocultural adjustment during cross-cultural transitions. International Journal of Intercultural Relations, 14, 449-464.

Shweder, R. A., \& Bourne, E. J. (1984). Does the concept of the person vary cross-culturally? In R. A. Schweder \& R. A. LeVine (Eds.), Culture theory: Essays on mind, self, and emotion (pp. 158-199). London: Cambridge University Press.

Singelis, T. M. (1994). The measurement of independent and interdependent self- construals. Personality and Social Psychology Bulletin, 20, 580-591.

Spaulding, S., \& Flack, M. J. (1976). The world's students in the United States: A review and evaluation of research on foreign students. New York: Praeger.

Steele, C. M. (1988). The psychology of self-affirmation: Sustaining the integrity of the self. In L. Berkowitz (Ed.), Advances in experimental social psychology (Vol. 21, pp. 261-302). New York: Academic Press.

Stening, B. W. (1979). Problems in cross-cultural contact: A literature review. International Journal of Intercultural Relations, 3, 269-313.

Tesser, A. (1988). Toward a self-evaluation maintenance model of social behavior. In L. Berkowitz (Ed.), Advances in experimental social psychology (Vol. 21, pp. 181-227). New York: Academic Press.

Trafimow, D., Triandis, H. C., \& Goto, S. G. (1991). Some tests of the distinction between the private self and the collective self. Journal of Personality and Social Psychology, 60, 649-655.

Triandis, H. C. (1989). The self and social behavior in differing cultural contexts. Psychological Review, 96, 506-520. 
Triandis, H. C., Bontempo, R., Villareal, M. J., Asai, M., \& Lucca, N. (1988). Individualism and collectivism: Cross-cultural perspectives on self-ingroup relationships. Journal of Personality and Social Psychology, 54, 323-338.

Triandis, H. C., Brislin, R., \& Hui, H. (1988). Cross-cultural training across the individualismcollectivism divide. International Journal of Intercultural Relations, 12, 269-289.

Triandis, H. C., Leung, K., Villareal, M., \& Clack, F. L. (1985). Allocentric vs. idiocentric tendencies: Convergent and discriminant validation. Journal of Research in Personality, 19, $395-415$.

Triandis, H. C., McCusker, C., \& Hui, C. H. (1990). Multimethod probes of individualism and collectivism. Journal of Personality and Social Psychology, 59, 1006-1020.

Tu, W. M. (1985). Selfhood and otherness in Confucian thought. In A. J. Marsella, G. DeVos, \& F.L.K. Hsu (Eds.), Culture and the self (pp. 231-251). New York: Tavistock.

Ward, C., \& Kennedy, A. (1992). Locus of control, mood disturbance, and social difficulty during cross-cultural transitions. International Journal of Intercultural Relations, 16, 175-194.

Ward, C., \& Kennedy, A. (1993). Where's the "culture" in cross-cultural transition? Journal of Cross-Cultural Psychology, 24, 221-249.

Weisz, J. R., Rothbaum, F. M., \& Blackburn, T. C. (1984). Standing out and standing in: The psychology of control in America and Japan. American Psychologist, 39, 955-969.

Wheeler, L., Reis, H. T., \& Bond, M. H. (1989). Collectivism and individualism in everyday social life: The middle kingdom and the melting pot. Journal of Personality and Social Psychology, 57, 79-86.

Widnall, S. (1988). AAAS presidential lecture: Voices from the pipeline. Science, 241, 17401745.

Wu, P. (1984). Varieties of the Chinese self. In V. Kavolis (Ed.), Designs of selfhood (pp. 107131). Canterbury, NJ: Associated University Press.

Yamaguchi, S. (1990). Personality and cognitive correlates of collectivism among the Japanese: Validation of collectivism scale. Unpublished paper, University of Tokyo, Department of Social Psychology.

Yamaguchi, S. (1994). Collectivism among the Japanese: A perspective from the self. In U. Kim, H. C. Triandis, C. Kagitcibasi, S. C. Choi, \& G. Yoon (Eds.), Individualism and collectivism: Theory, method, and applications (pp. 175-188). Thousand Oaks, CA: Sage.

Yamaguchi, S., Kuhlman, D. M., \& Sugimori, S. (1995). Personality correlates of allocentric tendencies in individualistic and collectivistic cultures. Journal of Cross-Cultural Psychology, 26, 658-672.

Yang, K. S. (1986). Chinese personality and its change. In M. H. Bond (Ed.), Psychology of the Chinese people (pp. 107-170). Hong Kong: Oxford University Press.

Yao, E. (1983). Chinese students in American universities. Texas Tech Journal of Education, 10, $35-42$.

Zaharna, R. S. (1989). Self-shock: The double-binding challenge of identity. International Journal of Intercultural Relations, 13, 501-525.

Susan E. Cross received her Ph.D. in social psychology from the University of Michigan and is currently Assistant Professor at Iowa State University. Her research interests include the self, social cognition, gender, and cultural psychology. 